\title{
Repetitive Transcranial Magnetic Stimulation of the Human Prefrontal Cortex Induces Dopamine Release in the Caudate Nucleus
}

\author{
Antonio P. Strafella, Tomáš Paus, Jennifer Barrett, and Alain Dagher \\ Montreal Neurological Institute, McGill University, Montréal, Québec, Canada H3A 2B4
}

Dopamine is implicated in movement, learning, and motivation, and in illnesses such as Parkinson's disease, schizophrenia, and drug addiction. Little is known about the control of dopamine release in humans, but research in experimental animals suggests that the prefrontal cortex plays an important role in regulating the release of dopamine in subcortical structures. Here we used $\left[{ }^{11} \mathrm{C}\right]$ raclopride and positron emission tomography to measure changes in extracellular dopamine concentration in vivo after repetitive transcranial magnetic stimulation (rTMS) of the dorsolateral prefrontal cortex in healthy human subjects. Repetitive TMS of the left dorsolateral prefrontal cor- tex caused a reduction in $\left[{ }^{11} \mathrm{C}\right]$ raclopride binding in the left dorsal caudate nucleus compared with rTMS of the left occipital cortex. There were no changes in binding in the putamen, nucleus accumbens, or right caudate. This shows that rTMS of the prefrontal cortex induces the release of endogenous dopamine in the ipsilateral caudate nucleus. This finding has implications for the therapeutic and research use of rTMS in neurological and psychiatric disorders.

Key words: positron emission tomography; transcranial magnetic stimulation; basal ganglia; prefrontal cortex; raclopride; dopamine
Animal experiments have shown that descending pathways from the frontal cortex modulate the release of dopamine in subcortical areas such as the striatum (Murase et al., 1993; Taber and Fibiger, 1993, 1995; Karreman and Moghaddam, 1996). There is evidence that, in the rat, this occurs both directly, via glutamatergic corticostriatal projections (Taber and Fibiger, 1995), and indirectly by an effect on mesostriatal dopamine neurons in the midbrain (Murase et al., 1993; Karreman and Moghaddam, 1996). This modulation may be relevant to the pathophysiology of disorders associated with subcortical dopamine dysfunction such as Parkinson's disease (Kish et al., 1988), schizophrenia (Grace, 1991), and depression (Willner, 1983). Little is known, however, about the anatomical pathways involved in the control of dopamine release in humans. Previous studies (Fox et al., 1997; Paus et al., 1997, 1998; Siebner et al., 1998) have shown that functional brain imaging can be used to measure changes in cerebral blood flow and glucose metabolism induced by transcranial magnetic stimulation. The aim of the present study was to use positron emission tomography (PET) to determine whether repetitive transcranial magnetic stimulation (rTMS) of the left mid-dorsolateral prefrontal cortex (MDL-PFC) induces dopamine release in the striatum of the human brain.

We used the dopamine receptor ligand $\left[{ }^{11} \mathrm{C}\right]$ raclopride to detect changes in levels of extracellular dopamine after rTMS. In vivo binding of benzamide tracers such as $\left[{ }^{11} \mathrm{C}\right]$ raclopride has been shown to be inversely proportional to levels of extracellular dopamine (Endres et al., 1997; Laruelle et al., 1997). In humans, this method has been used to measure dopamine release in response to drugs (Dewey et al., 1993; Smith et al., 1997; Volkow et al., 1997; Breier et al., 1998) and behavioral tasks (Koepp et al.,

\footnotetext{
Received March 28, 2001; revised May 3, 2001; accepted May 9, 2001.

Correspondence should be addressed to Dr. Antonio P. Strafella, Montreal Neurological Institute, Webster 2B, 3801 University Street, Montréal, Quebec, Canada H3A 2B4. E-mail: antonio@bic.mni.mcgill.ca.
}

Copyright (C) 2001 Society for Neuroscience 0270-6474/01/210001-04\$15.00/0
1998). We now report results from eight healthy volunteers who underwent two $\left[{ }^{11} \mathrm{C}\right]$ raclopride PET scans, one immediately after rTMS of the left MDL-PFC and one after rTMS of the left occipital cortex for control purposes. Statistical parametric maps representing the change in $\left[{ }^{11} \mathrm{C}\right]$ raclopride binding potential (BP) were generated to infer changes in the levels of extracellular dopamine (Aston et al., 2000).

\section{MATERIALS AND METHODS}

Experimental design. Five female and three male healthy volunteers (ages, 19-42 years) participated in the study after having given written informed consent. All subjects but one were right-handed, and none had a history of neurological or psychiatric illness. Each underwent two $\left[{ }^{11} \mathrm{C}\right]$ raclopride PET scans (total injected dose, $20 \mathrm{mCi}$ ), one after rTMS of the left MDL-PFC and one after rTMS of the left occipital cortex. The scan order was randomized across subjects, and the scans were always performed at the same time in the afternoon on consecutive days. Autonomic parameters and subjective ratings were collected throughout both sessions of rTMS and PET. During the study, the subjects kept their eyes closed; earplugs were used to attenuate the coil-generated clicks. The experiments were approved by the Research Ethics Committee of the Montreal Neurological Institute and Hospital.

Transcranial magnetic stimulation. Repetitive TMS was performed with the Cadwell high-speed magnetic stimulator (Cadwell Laboratories, Kennewick, WA) using a circular coil (external diameter, $9 \mathrm{~cm}$ ). The coil was

This article is published in The Journal of Neuroscience, Rapid Communications Section, which publishes brief, peerreviewed papers online, not in print. Rapid Communications are posted online approximately one month earlier than they would appear if printed. They are listed in the Table of Contents of the next open issue of JNeurosci. Cite this article as: JNeurosci, 2001, 21:RC157 (1-4). The publication date is the date of posting online at www.jneurosci.org.

http://www.jneurosci.org/cgi/content/full/5457 
A

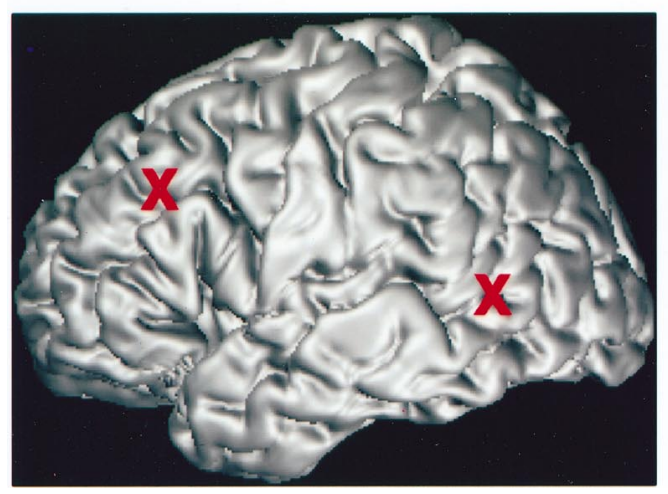

B

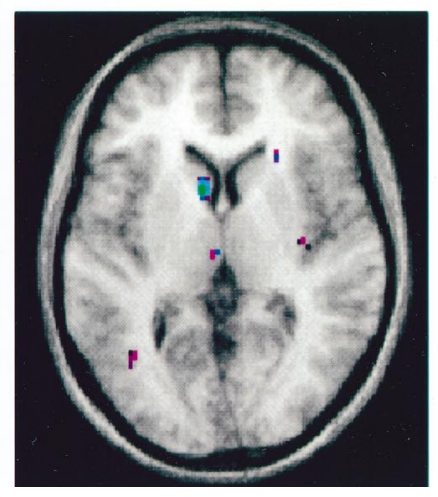

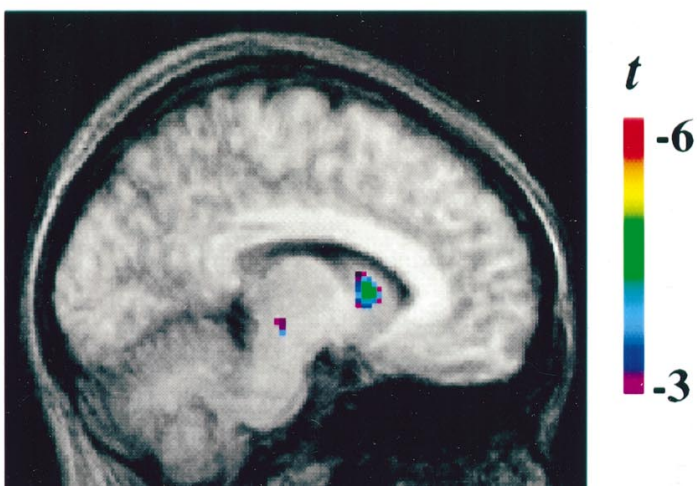

Figure 1. A, Location (red markers) of the two stimulation sites, the left mid-dorsolateral prefrontal cortex and the left occipital cortex, on the MRI of one subject in stereotaxic space. $B$, Transverse $(Z=6$; left panel $)$ and sagittal $(X=-8$; right panel $)$ sections of the statistical parametric map of the change in $\left[{ }^{11} \mathrm{C}\right]$ raclopride BP overlaid on the average MRI of all subjects in stereotaxic space. The peak in the left caudate nucleus shows the location at which $\left[{ }^{11} \mathrm{C}\right]$ raclopride BP changed significantly after rTMS of the left mid-dorsolateral prefrontal cortex.

held outside the scanner in a fixed position by a mechanical arm over the left MDL-PFC or the left occipital cortex. It was positioned so that the anterior tip of the coil was closest to the cortical site, with the rest of the coil tilted away from the skull. The induced current under the coil flowed in a lateromedial direction. Three rTMS blocks were delivered, each block separated by a 10 min interval. In each block, 15 10-pulse trains of $1 \mathrm{sec}$ duration were delivered at a stimulation frequency of $10 \mathrm{~Hz}$ and with a between-train interval of $10 \mathrm{sec}$. Thus, a total of 450 stimuli were delivered over a period of $30 \mathrm{~min}$ preceding the start of PET acquisition. The stimulus intensities, which were expressed as a percentage of the maximum stimulator output, were set at the resting motor threshold (MT). MT was defined as the lowest stimulus intensity able to elicit, in the right first dorsal interosseous (FDI), five motor-evoked potentials (MEPs) of at least $50 \mu \mathrm{V}$ amplitude in a series of 10 stimuli delivered over the left primary motor cortex at intervals $>5 \mathrm{sec}$. MEPs were recorded from the right FDI muscle with $\mathrm{AgCl}$ surface electrodes that were fixed on the skin with a belly-tendon montage. The EMG signal was filtered $(10 \mathrm{~Hz}-1 \mathrm{kHz}$ bandpass $)$ and displayed on a computer screen. Repetitive TMS at MT over either of the experimental stimulation sites, MDL-PFC and occipital cortex, did not induce EMG activation in the right FDI.

Subjective ratings and autonomic measures. The following autonomic parameters were collected for 2.5 min during a baseline period at the start of the study and during the rest periods after each block of rTMS: electrodermal level, respiration rate, and temperature. After the baseline period and after each rest period, subjects completed a behavioral questionnaire in which they rated the level of their comfort, fatigue, anxiety, mood, irritation, and pain. Ratings were made on a seven-point Likert scale ranging from -3 to 3 , with -3 indicating the highest negative level and 3 indicating the highest positive level for each dimen- sion. Baseline ratings focused on how subjects were currently feeling, whereas ratings after blocks of rTMS focused on how subjects felt during the preceding rTMS stimulation.

Location of the target site. To target the desired sites in all of our subjects, we used a procedure that takes advantage of the standardized stereotaxic space of Talairach and Tournoux (1988) and frameless stereotaxy (Peters et al., 1996). A high-resolution magnetic resonance image (MRI) of the subject's brain was acquired and transformed into standardized stereotaxic space (Collins et al., 1994). The chosen Talairach coordinates of the left MDL-PFC $(X=-40, Y=32, Z=30)$ (Petrides et al., 1993) and left occipital cortex $(X=-56, Y=-58, Z=-3)$ were converted into each subject's native MRI space using the reversed nativeto-Talairach transformation (Paus et al., 1997). The positioning of the TMS coil over these locations, marked on the native MRI, was performed with the aid of a frameless stereotaxic system (Paus, 1999).

Positron emission tomography. PET scans were obtained with a CTI/ Siemens HR plus tomograph operated in 3-D mode, yielding images of resolution $4.2 \mathrm{~mm}$ full width at half maximum. Within $5 \mathrm{~min}$ of the completion of the rTMS session, $10 \mathrm{mCi}$ of $\left[{ }^{11} \mathrm{C}\right]$ raclopride was injected into the left antecubital vein over $60 \mathrm{sec}$, and emission data were acquired over a period of $60 \mathrm{~min}$ in 26 frames of progressively increasing duration. After the emission scan, a transmission scan was performed with a rotating radioactive source for attenuation correction.

PET frames were summed, registered to the corresponding MRI (Woods et al., 1993), and transformed into standardized stereotaxic space (Talairach and Tournoux, 1988) by means of an automated featurematching algorithm (Collins et al., 1994). Voxel-wise [ $\left.{ }^{11} \mathrm{C}\right]$ raclopride BP was calculated using a simplified reference tissue method (Lammertsma and Hume, 1996; Gunn et al., 1997) to generate statistical parametric

\section{Table 1. $\left[{ }^{11} \mathrm{C}\right]$ raclopride binding potential in the caudate nucleus after stimulation of the prefrontal and occipital cortex}

\begin{tabular}{|c|c|c|c|c|c|c|c|}
\hline \multirow[b]{2}{*}{ Subject } & \multirow[b]{2}{*}{ TMS (\%) } & \multicolumn{3}{|c|}{ L caudate BP } & \multicolumn{3}{|c|}{$\mathrm{R}$ caudate BP } \\
\hline & & L OCC & L PFC & $\%$ & L OCC & L PFC & $\%$ \\
\hline 1 & 44 & 1.592 & 1.439 & -9.61 & 1.408 & 1.531 & 8.73 \\
\hline 2 & 51 & 2.109 & 1.957 & -7.20 & 2.276 & 2.304 & 1.23 \\
\hline 3 & 52 & 1.541 & 1.428 & -7.33 & 1.562 & 1.633 & 4.54 \\
\hline 4 & 48 & 1.921 & 1.805 & -6.03 & 1.431 & 1.402 & -2.02 \\
\hline 5 & 48 & 1.827 & 1.749 & -4.26 & 1.587 & 1.794 & 13.04 \\
\hline 6 & 50 & 1.431 & 1.347 & -5.87 & 1.667 & 1.663 & -0.23 \\
\hline 7 & 46 & 1.518 & 1.328 & -12.51 & 1.698 & 1.538 & -9.42 \\
\hline 8 & 52 & 2.451 & 2.303 & -6.03 & 2.496 & 2.559 & 2.52 \\
\hline Mean & & 1.798 & 1.669 & -7.36 & 1.765 & 1.803 & 2.29 \\
\hline SD & & 0.350 & 0.346 & 2.58 & 0.400 & 0.409 & 6.82 \\
\hline
\end{tabular}

In each subject, BP values from the left and right caudate nuclei were extracted with two regions of interest drawn on three adjacent axial sections $(z, 4-8 \mathrm{~mm})$ of the subject's MRI in stereotaxic space and confined to the head of the caudate nucleus. TMS, Transcranial magnetic stimulation intensity; BP, $\left[{ }^{11} \mathrm{C}\right] \mathrm{raclopride}$ binding potential; $\mathrm{L}$, left; $\mathrm{R}$, right; OCC, occipital cortex stimulation; PFC, mid-dorsolateral prefrontal cortex stimulation. 
Table 2. Mean behavioral ratings of the eight subjects before and after rTMS of the prefrontal and occipital cortex

\begin{tabular}{|c|c|c|c|c|}
\hline & \multicolumn{2}{|l|}{ Occipital } & \multicolumn{2}{|l|}{ Prefrontal } \\
\hline & Before rTMS & After rTMS & Before rTMS & After rTMS \\
\hline Discomfort-comfort & $1.63(0.52)$ & $1.33(1.42)$ & $1.25(1.16)$ & $1.75(1.00)$ \\
\hline Anxious-calm & $2.25(0.71)$ & $2.00(1.08)$ & $2.25(0.46)$ & $2.50(0.62)$ \\
\hline Fatigued-rested & $2.00(0.53)$ & $2.16(0.56)$ & $1.25(1.46)$ & $2.08(1.23)$ \\
\hline Sad-happy & $1.75(0.71)$ & $1.71(0.74)$ & $1.40(0.74)$ & $1.50(0.67)$ \\
\hline Irritated-soothed & $1.90(0.83)$ & $1.50(1.25)$ & $1.75(0.88)$ & $1.79(0.97)$ \\
\hline Feel pain-do not feel pain & $1.63(1.41)$ & $1.75(1.15)$ & $1.13(1.88)$ & $1.50(1.32)$ \\
\hline
\end{tabular}

Numbers in parentheses are SDs.

images of change in BP (Aston et al., 2000). Only peaks falling within the striatum were considered for further analysis, because this is the only brain structure in which receptor-specific $\left[{ }^{11} \mathrm{C}\right]$ raclopride binding is detected. A reduction in $\left[{ }^{11} \mathrm{C}\right]$ raclopride $\mathrm{BP}$ is indicative of an increase in extracellular dopamine concentration (Endres et al., 1997; Laruelle et al., 1997). In each subject, BP values from the left and right caudate nuclei were extracted with two regions of interest drawn on three adjacent axial sections $(z, 4-8 \mathrm{~mm})$ of the subject's MRI in stereotaxic space and confined to the head of the caudate nucleus. These BP values were analyzed using repeated measures ANOVA.

\section{RESULTS}

Repetitive TMS of the left MDL-PFC decreased [ $\left.{ }^{11} \mathrm{C}\right]$ raclopride $\mathrm{BP}$ in the left caudate nucleus compared with rTMS of the left occipital cortex (Fig. 1, Table 1). This is most likely because of an increase in extracellular dopamine concentration after prefrontal stimulation. Table 1 shows BP values from the left and right caudate nuclei that were derived from a region-of-interest drawn on the MRI of each subject at the level of the statistical peak revealed by the parametric map. Repeated measures ANOVA revealed a significant effect of stimulation site for the left caudate nucleus $\left(F_{(1,7)}=91.3 ; p<0.0001\right)$, but not for the right caudate nucleus $\left(F_{(1,7)}=0.94 ; \mathrm{NS}\right)$. The mean magnitude of change in $\left[{ }^{11} \mathrm{C}\right]$ raclopride BP in the left caudate nucleus was $-7.3 \%$. There was no significant relationship between the intensity of TMS and the change in $\left[{ }^{11} \mathrm{C}\right]$ raclopride BP. Repetitive TMS of the left MDL-PFC did not lead to a statistically significant change in $\left[{ }^{11} \mathrm{C}\right]$ raclopride $\mathrm{BP}$ in the putamen or the nucleus accumbens. The autonomic measures and replies to the questionnaires were analyzed using repeated measures ANOVA. Because there were no significant differences between the three rTMS periods, data were pooled. ANOVA revealed no significant main effect of site of stimulation (MDL-PFC, occipital) or condition (before and after rTMS) nor any significant site-by-condition interaction (Tables 2, 3).

\section{DISCUSSION}

We have shown that rTMS of the left MDL-PFC can evoke release of striatal dopamine in humans, as detected by $\left[{ }^{11} \mathrm{C}\right] \mathrm{ra}-$ clopride PET. The fact that the BP change was seen only in the ipsilateral head of the caudate nucleus suggests that corticostriatal fibers originating in the MDL-PFC were involved in promoting local dopamine release at their striatal target site. Anatomical studies in rhesus monkeys have shown that the MDL-PFC projects to the dorsal caudate nucleus (Selemon and GoldmanRakic, 1985; Yeterian and Pandya, 1991). Moreover, corticostriatal fibers originating in the PFC are thought to project only or predominantly to the ipsilateral striatum (Kemp and Powell, 1970). Thus, the area of statistically significant change in $\left[{ }^{11} \mathrm{C}\right] \mathrm{ra}-$ clopride binding in our study corresponds to the major projection site of corticostriatal fibers originating in the stimulated area in MDL-PFC.

These excitatory corticostriatal projections could promote dopamine release by a local effect of glutamate on adjacent nigrostriatal nerve terminals (Cheramy et al., 1986). Such an effect may be mediated by ionotropic (Leviel et al., 1990) or metabotropic (Taber and Fibiger, 1995) glutamate receptors in the striatum, perhaps acting on dopamine nerve terminals via nitric oxide (Hanbauer et al., 1992). The existence of this mechanism is supported by the fact that cortical neurons originating in the PFC and dopamine neurons from the ventral tegmental area synapse in close proximity to one another on the spines of striatal medium spiny neurons (Sesack and Pickel, 1992).

However, the possibility of indirect modulation of striatal dopamine via corticonigral projections also must be taken in consideration. In rats, stimulation of the PFC can promote bilateral striatal dopamine release by activation of dopamine neurons in the ventral tegmental area (Murase et al., 1993; Taber et al., 1995; Karreman and Moghaddam, 1996). This could occur via direct and indirect connections between the PFC and midbrain dopamine neurons. On the basis of these animal experiments, one would expect that dopamine released by this mechanism would not be confined to one area of the dorsal caudate, but rather that it would involve the neostriatum and nucleus accumbens, possibly bilaterally (Karreman and Moghaddam, 1996). In this experiment, we did not detect such widespread release of striatal dopamine, suggesting that our results reflect only the action of the

Table 3. Mean autonomic activity of the eight subjects before and after rTMS of the prefrontal and occipital cortex

\begin{tabular}{|c|c|c|c|c|}
\hline & \multicolumn{2}{|l|}{ Occipital } & \multicolumn{2}{|l|}{ Prefrontal } \\
\hline & Before rTMS & After rTMS & Before rTMS & After rTMS \\
\hline Electrodermal level $(\mu \Omega)$ & $2.89(2.26)$ & $2.99(2.90)$ & $2.61(2.49)$ & $2.63(2.24)$ \\
\hline Respiration rate & $14.32(3.72)$ & $15.41(2.38)$ & $13.20(3.32)$ & $14.97(2.48)$ \\
\hline Temperature $\left({ }^{\circ} \mathrm{C}\right)$ & $30.51(10.33)$ & $29.72(8.87)$ & $27.43(7.06)$ & $28.18(7.85)$ \\
\hline
\end{tabular}

Numbers in parentheses are SDs. 
direct corticostriatal projections. Grace (1991) has suggested that dopamine released under direct corticostriatal influence diffuses into the extrasynaptic space, whereas the dopamine that is released because of midbrain dopamine neuron burst firing is rapidly cleared from the synapse by reuptake into the nerve terminal. It is possible that the $\left[{ }^{11} \mathrm{C}\right]$ raclopride PET technique is most sensitive to extrasynaptic dopamine.

The rTMS-induced release of dopamine in the caudate nucleus could be a consequence of direct stimulation of the corticostriatal axons (Rothwell, 1997), indirect trans-synaptic activation of corticostriatal neurons caused by a reduction in GABA-mediated intracortical inhibition (Chen et al., 1997; Nakamura et al., 1997; Rothwell, 1997; Pascual-Leone et al., 1998), or both.

In conclusion, these results show for the first time the ability of PET to detect in humans changes in levels of extracellular dopamine after rTMS of MDL-PFC. This technique opens up new avenues for in vivo studies of corticostriatal interactions in humans and for clinical studies of neurological and psychiatric disorders associated with subcortical dopamine dysfunction.

\section{REFERENCES}

Aston JA, Gunn RN, Worsley KJ, Ma Y, Evans AC, Dagher A (2000) A statistical method for the analysis of positron emission tomography neuroreceptor ligand data. NeuroImage 12:245-256.

Breier A, Su TP, Saunders R, Carson RE, Kolachana BS, De Bartolomeis A, Weinberger DR, Weisenfeld N, Malhotra AK, Eckelman WC, Pickar D (1998) Effects of NMDA antagonism on striatal dopamine release in healthy subjects: application of a novel PET approach. Synapse 29:142-147.

Chen R, Classen J, Gerloff C, Celnik P, Wassermann EM, Hallett M, Cohen LG (1997) Depression of motor cortex excitability by lowfrequency transcranial magnetic stimulation. Neurology 48:1398-1403.

Cheramy A, Romo R, Godeheu G, Baruch P, Glowinski J (1986) In vivo presynaptic control of dopamine release in the cat caudate nucleus. II. Facilitatory or inhibitor influence of L-glutamate. Neuroscience 19:1081-1090.

Collins DL, Neelin P, Peters TM, Evans AC (1994) Automatic 3D intersubject registration of MR volumetric data in standardized Talairach space. J Comput Assist Tomogr 18:192-205.

Dewey SL, Smith GS, Logan J, Brodie JD, Simkowitz P, MacGregor RR, Fowler JS, Volkow ND, Wolf AP (1993) Effect of central cholinergic blockade on striatal dopamine release measured with positron emission tomography in normal subjects. Proc Natl Acad Sci USA 90:11816-11820.

Endres CJ, Kolachana BS, Saunders RC, Su T, Weinberger D, Breier A, Eckelman WC, Carson RE (1997) Kinetic modelling of ${ }^{11}$ Clraclopride: combined PET-microdialysis studies. J Cereb Blood Flow Metab 9:932-942.

Fox P, Ingham R, George MS, Mayberg H, Ingham J, Roby J, Martin C, Jerabek P (1997) Imaging human intra-cerebral connectivity by PET during TMS. NeuroReport 8:2787-2791.

Grace AA (1991). Phasic versus tonic dopamine release and the modulation of dopamine system responsivity: a hypothesis for the etiology of schizophrenia. Neuroscience 41:1-24.

Gunn RN, Lammertsma A, Hume SP, Cunningham VJ (1997) Parametric imaging of ligand-receptor binding in PET using a simplified reference region model. NeuroImage 6:279-287.

Hanbauer I, Wink D, Osawa Y, Edelman GM, Gally JA (1992) Role of nitric oxide in NMDA-evoked release of $\left[{ }^{3} \mathrm{H}\right]$-dopamine from striatal slices. NeuroReport 3:409-412.

Karreman M, Moghaddam B (1996) The prefrontal cortex regulates the basal release of dopamine in the limbic striatum: an effect mediated by ventral tegmental area. J Neurochem 66:589-598.

Kemp JM, Powell TPS (1970) The cortico-striate projection in the monkey. Brain 93:525-546.

Kish SJ, Shannak K, Hornykiewicz O (1988) Uneven pattern of dopamine loss in the striatum of patients with idiopathic Parkinson's disease. Pathophysiologic and clinical implications. N Engl J Med 318:876-880.

Koepp MJ, Gunn RN, Lawrence AD, Cunningham VJ, Dagher A, Jones T, Brooks DJ, Bench CJ, Grasby PM (1998) Evidence for striatal dopamine release during a video game. Nature 393:266-268.
Lammertsma AA, Hume SP (1996) Simplified reference tissue model for PET receptor studies. NeuroImage 4:153-158.

Laruelle M, Iyer RN, Al-Tikriti MS, Zea-Ponce Y, Malison R, Zoghbi SS, Baldwin RM, Kung HF, Charney DS, Hoffer PB, Innis RB, Bradberry CV (1997) Microdialysis and SPECT measurements of amphetamine-induced dopamine release in nonhuman primates. Synapse 25:1-14.

Leviel V, Gobert A, Guibert B (1990) The glutamate-mediated release of dopamine in the rat striatum: further characterization of the dual excitatory-inhibitory function. Neuroscience 39:305-312.

Murase S, Grenhoff J, Chouvet G, Gonon FG, Svensson TH (1993) Prefrontal cortex regulates burst firing and transmitter release in rat mesolimbic dopamine neurons studied in vivo. Neurosci Lett 157:53-56.

Nakamura H, Kitagawa H, Kawaguchi Y, Tsuji H (1997) Intracortical facilitation and inhibition after transcranial magnetic stimulation in conscious humans. J Physiol (Lond) 498:871-823.

Pascual-Leone A, Tormos JM, Keenan J, Tarazona F, Canete C, Catala MD (1998) Study and modulation of human cortical excitability with transcranial magnetic stimulation. J Clin Neurophysiol 15:333-343.

Paus T (1999) Imaging the brain before, during, and after transcranial magnetic stimulation. Neuropsychologia 37:219-224.

Paus T, Jech R, Thompson CJ, Comeau R, Peters T, Evans AC (1997) Transcranial magnetic stimulation during positron emission tomography: a new method for studying connectivity of the human cerebral cortex. J Neurosci 17:3178-3184.

Paus T, Jech R, Thompson CJ, Comeau R, Peters T, Evans AC (1998) Dose-dependent reduction of cerebral blood flow during rapid-rate transcranial magnetic stimulation of the human sensorimotor cortex. J Neurophysiol 79:1102-1107.

Peters T, Davey B, Munger P, Comeau R, Evans A, Olivier A (1996) Three-dimensional multimodal image-guidance for neurosurgery. IEEE Trans Med Imag 15:121-128.

Petrides M, Alivisatos B, Evans AC, Meyer E (1993) Dissociation of human mid-dorsolateral from posterior dorsolateral frontal cortex in memory processing. Proc Natl Acad Sci USA 90:873-877.

Rothwell JC (1997) Techniques and mechanisms of action of transcranial magnetic stimulation of the human motor cortex. J Neurosci Methods 74:113-122.

Selemon LD, Goldman-Rakic PS (1985) Longitudinal topography and interdigitation of corticostriatal projections in the rhesus monkey. J Neurosci 5:776-794.

Sesack SR, Pickel VM (1992) Prefrontal cortical efferents in the rat synapse on unlabeled neuronal targets of catecholamine terminals in the nucleus accumbens septi and on dopamine neurons in the ventral tegmental area. J Comp Neurol 320:145-160.

Siebner HR, Willoch F, Peller M, Auer C, Boecker H, Conrad B, Bartenstein P (1998) Imaging brain activation induced by long trains of repetitive transcranial magnetic stimulation. NeuroReport 9:943-948.

Smith GS, Dewey SL, Brodie JD, Logan J, Vitkum SA, Simkowitz P, Schloesser R, Alexoff DA, Hurley A, Cooper T, Volkow ND (1997) Serotonergic modulation of dopamine measured with $\left[{ }^{11} \mathrm{C}\right]$ raclopride and PET in normal human subjects. Am J Psychiatry 154:490-496.

Taber MT, Fibiger HC (1993) Electrical stimulation of the medial prefrontal cortex increases dopamine release in the striatum. Neuropsychopharmacology 9:271-275.

Taber MT, Fibiger HC (1995) Electrical stimulation of the prefrontal cortex increases dopamine release in the nucleus accumbens of the rat: modulation by metabotropic glutamate receptors. J Neurosci 15:3896-3904.

Taber MT, Das S, Fibiger HC (1995) Cortical regulation of subcortical dopamine release: mediation via the ventral tegmental area. J Neurochem 65:1407-1410.

Talairach J, Tournoux P (1988) Co-planar stereotactic atlas of the human brain: 3-dimensional proportional system, an approach to cerebral imaging. Stuttgard, Germany: Thieme.

Volkow ND, Wang GJ, Fowler JS, Logan J, Gatley SJ, Hitzemann R, Chen AD, Dewey SL, Pappas N (1997) Decreased striatal dopaminergic responsiveness in detoxified cocaine-dependent subjects. Nature 386:830-833.

Willner P (1983) Dopamine and depression: a review of recent evidence. I. Empirical studies. Brain Res Rev 6:211-224.

Woods RP, Mazziotta JC, Cherry SR (1993) MRI-PET registration with automated algorithm. J Comput Assist Tomogr 17:536-546.

Yeterian EH, Pandya DN (1991) Prefrontostriatal connections in relation to cortical architectonic organization in rhesus monkeys. J Comp Neurol 312:43-67. 